\title{
Recovery of psychomotor function after propofol sedation is prolonged in the elderly
}

\section{[Le rétablissement de la fonction psychomotrice après une sédation au propofol se} prolonge chez les gens âgés]

Mio Shinozaki MD, Yosuke Usui MD, Shigeki Yamaguchi MD PhD, Yasuhisa Okuda MD PhD, Toshimitsu Kitajima MD PhD

Purpose: To assess the effects of age on recovery of psychomotor function for propofol sedation during spinal anesthesia.

Methods: Propofol was continuously infused during surgery and spinal anesthesia in 15 elderly patients (65-85 yr-old) and 15 younger patients (20-50 yr-old). Infusion rates were adjusted to maintain an appropriate level of sedation using the bispectral index (range 60-70). The sedative infusion was discontinued at the end of surgery. The early recovery times from the end of propofol infusion to opening of eyes on command, sustaining a hand grip, and recall of name were noted. Psychomotor function, as measured by the Trieger's dot test, was evaluated before anesthesia and 30, 60, 90, 120 min after the end of propofol infusion.

Results: The duration of anesthesia was 142 \pm 55 min and $134 \pm$ $61 \mathrm{~min}$ in the elderly and younger patients, respectively. No differences were observed in early recovery times between elderly and younger patients (opened their eyes on command, $6.3 \pm 4.0 \mathrm{~min}$ and $5.2 \pm 2.6 \mathrm{~min}$; sustained a hand grip, $7.2 \pm 3.9 \mathrm{~min}$ and 6.1 $\pm 3.5 \mathrm{~min}$ and recalled their name, $8.0 \pm 4.5 \mathrm{~min}$ and $6.5 \pm 3.8$ $\min , P>0.05)$. The recovery of psychomotor function in the elderly took longer compared with the younger patients, and psychomotor function in the elderly recovered at 120 min after the end of propofol infusion.

Conclusion: Early recovery times following propofol sedation is similar between elderly and younger patients, but recovery of psychomotor function in the elderly is delayed compared with younger patients.

Objectif: Évaluer les effets de l'âge sur la récupération de la fonction psychomotrice à la suite d'une sédation au propofol pendant la rachianesthésie.

Méthode : Une perfusion continue de propofol a été utilisée pendant une intervention chirurgicale sous rachianesthésie chez 15 patients âgés (65-85 ans) et 15 patients plus jeunes (20-50 ans). Les vitesses de perfusion ont été réglées de façon à maintenir un niveau approprié de sédation à l'aide de l'index bispectral (intervalle de 60-70). La perfusion a été interrompue à la fin de l'opération. On a noté le temps écoulé entre la fin de la perfusion jusqu'à l'ouverture des yeux sur commande, le moment où le patient peut maintenir la préhension de la main et se nommer. La fonction psychomotrice, mesurée par le test de Trieger, a été évaluée à 30, 60, 90 et 120 min après la fin de la perfusion de propofol.

Résultats : La durée de l'anesthésie a été de $142 \pm 55$ min et de $134 \pm 61$ min chez les patients âgés et les plus jeunes, respectivement. Aucune différence des temps de récupération précoce n'a été observée entre les patients âgés et les autres (l'ouverture des yeux sur commande : 6,3 \pm 4,0 min et 5,2 \pm 2,6 min ; la préhension de la main : 7,2 $\pm 3,9$ min et $6,1 \pm 3,5$ min et la capacité de se nommer : $8.0 \pm 4,5 \mathrm{~min}$ et $6,5 \pm 3,8 \mathrm{~min}, P>0,05)$. Le rétablissement de la fonction psychomotrice a été plus long chez les gens âgés comparés aux plus jeunes et s'est produit à 120 min après la fin de la perfusion de propofol chez les patients âgés.

Conclusion : Les temps de récupération précoce qui suit la sédation au propofol sont similaires chez les patients âgés ou plus jeunes, mais le rétablissement de la fonction psychomotrice est retardé chez les patients âgés comparés à des patients plus jeunes.

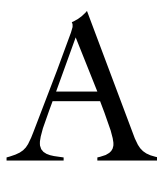
GE is one of the many factors known to influence recovery following anesthesia. ${ }^{1-5}$ Propofol is commonly used to provide sedation during spinal anesthesia because of its high clearance rate and short elimination halflife. ${ }^{6-9}$ However, there have, so far, been few reports on the recovery of psychomotor function after propofol sedation in the elderly. The purpose of this study is to clarify the influence of age on the recovery of psy-

From the First Department of Anesthesiology, Dokkyo University School of Medicine, Mibu, Tochigi, Japan.

Address correspondence to: Dr. Mio Shinozaki, First Department of Anesthesiology, Dokkyo University School of Medicine, Mibu,

Tochigi 321-0293, Japan. Phone: 81-282-86-7089; Fax: 81-282-86-0478; E-mail: mio28@mug.biglobe.ne.jp

Accepted for publication December 20, 2001.

Revision accepted July 22, 2002. 
chomotor function for propofol sedation after spinal anesthesia using the Trieger's dot test. In this study, we used bispectral index (BIS) values to maintain an appropriate level of sedation during propofol infusion.

\section{Methods}

After obtaining approval of the hospital Ethics Committee and informed consent, we studied 15 elderly patients (65-85 yr-old; group E) and 15 younger patients (20-50 yr-old; group Y), ASA physical status I-II, scheduled to undergo orthopedic surgery under spinal anesthesia. Exclusion criteria were a history of cardiac, pulmonary, hepatic or renal disease, morbid obesity, or disabling neuropsychiatric disorders. In addition, none had received central nervous system depressant medication which might affect anesthesia or recovery.

The Trieger's dot test, a psychomotor function test, was performed before and after anesthesia. ${ }^{10}$ The Trieger's dot test was conducted by a single anesthesiologist. This test consists of joining together 42 dots by a line which represents a drawing. The number of dots missed (NDM) represent the total number of dots that were not connected. The sum of the distance (SD) represents the cumulative shorter distance (in millimetres) between the drawn line and missed dots. The maximum distance of dots missed (MDDM) represents the longest distance (in millimetres) between the drawn line and missed dots.

All patients were premedicated with atropine sulfate $0.25-0.5 \mathrm{mg}$ im $30 \mathrm{~min}$ before the induction of anesthesia. After arriving in the operating room, routine monitoring and venous cannulation were performed. Dural puncture was performed at the L3-L4, or L4-L5 interspace and $0.5 \%$ bupivacaine $3-4 \mathrm{~mL}$ were injected.

To measure BIS values during propofol infusion, electrodes were placed on the forehead of each patient. The electrodes used were disposable BisSensor ${ }^{\circledR}$ strips (Aspect Medical Systems Inc., Newton, MA, USA). BIS values from the electroencephalogram (EEG) were calculated with an aspect EEG monitor (Model Al050, Aspect Medical Systems, software version 3.3).

A face mask was applied to administer oxygen 3 $\mathrm{L} \cdot \mathrm{min}^{-1}$. Propofol infusion was commenced at 6 $\mathrm{mg} \cdot \mathrm{kg}^{-1} \cdot \mathrm{hr}^{-1}$ for ten minutes via a syringe pump and the infusion rate adjusted to maintain an appropriate level of sedation using BIS values (range 60-70). ${ }^{11,12}$ The infusion was discontinued at the end of surgery.

The early recovery time ( $\mathrm{min}$ ) from the end of propofol infusion to opening of eyes on command, sustaining a hand grip and recall of name were noted by a single anesthesiologist. The Trieger's dot test was administered before anesthesia and 30, 60, 90, 120 min after discontinuation of propofol infusion. The presence of any complication was noted, particularly in relation to respiratory or airway problems, nausea or vomiting, and headache.

Data were expressed as mean \pm SD. Statistical analyses within a group were performed by repeatedmeasure analysis of variance (repeated measurement ANOVA) with Bonferroni's correction. Comparisons between both groups were made by applying the Mann-Whitney test. The threshold for statistical significance was $P<0.05$.

\section{Results}

Patient details are shown in the Table. Except for age, no significant difference was found between the two groups. The mean infusion rate of propofol was also comparable in each group. Quality and ease of control of sedation were good in both groups using the BIS values. The values were maintained $60-70$ during anesthesia.

\section{Evaluation of intraoperative and postoperative complications}

Airway maintenance was excellent in all patients, with no evidence of coughing, laryngospasm, airway obstruction or apnea. One patient in group $\mathrm{E}$ and two patients in group Y complained of a slight burning pain in the arm within five minutes after commencing propofol infusion. One patient in group E felt nausea postoperatively. Two patients in each group noticed euphoria postoperatively.

\section{Assessment of early recovery time}

Early recovery times were similar in both groups. There was no significant difference in the interval from the end of propofol infusion until patients opened their eyes on command $(6.3 \pm 4.0 \mathrm{~min}$ and

TABLE Demographic data and infusion rate of propofol

\begin{tabular}{lll}
\hline & Elderly group & $\begin{array}{l}\text { Younger } \\
\text { patients } \\
\text { group } \\
(n=15)\end{array}$ \\
\hline Age $(\mathrm{yr})$ & $72 \pm 4$ & $38 \pm 8^{*}$ \\
Weight $(\mathrm{kg})$ & $52 \pm 8$ & $65 \pm 14$ \\
Height $(\mathrm{cm})$ & $150 \pm 10$ & $157 \pm 9$ \\
Duration of anesthesia (min) & $142 \pm 55$ & $134 \pm 61$ \\
$\begin{array}{l}\text { Duration of surgery (min) } \\
\text { Mean infusion rate of propofol } \\
\left(\mathrm{mg} \cdot \mathrm{kg}^{-1} \cdot \mathrm{hr}^{-1}\right)\end{array}$ & $124 \pm 38$ & $101 \pm 61$ \\
\hline
\end{tabular}

Values expressed as mean $\pm \mathrm{SD}$. ${ }^{*} P<0.05$ vs elderly group. 


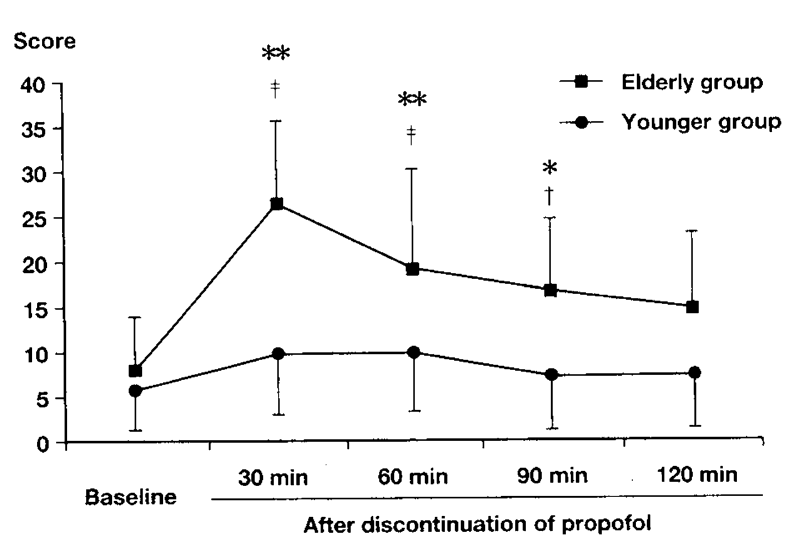

FIGURE 1 Number of dots missed. ${ }^{*} P<0.05$ vs younger group; ${ }^{*} P<0.01$ vs younger group; $\uparrow P<0.05$ vs baseline; $\ddagger P<$ 0.01 vs baseline.

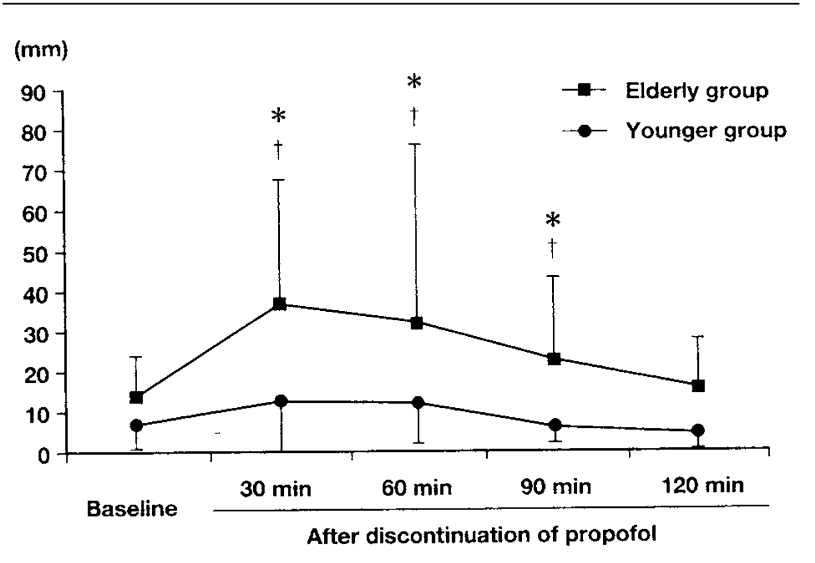

FIGURE 2 Sum of distance. ${ }^{*} P<0.05$ vs younger group; $\dagger P<$ 0.05 ps baseline.

$5.2 \pm 2.6 \mathrm{~min}, P>0.05$, in groups $\mathrm{E}$ and $\mathrm{Y}$, respectively), sustained a hand grip $(7.2 \pm 3.9 \mathrm{~min}$ and $6.1 \pm$ $3.5 \mathrm{~min}, P>0.05$, in groups $\mathrm{E}$ and $\mathrm{Y}$, respectively) and recalled their name $(8.0 \pm 4.5 \mathrm{~min}$ and $6.5 \pm 3.8$ min, $P>0.05$, in groups $\mathrm{E}$ and $\mathrm{Y}$, respectively).

\section{Assessment of the Trieger's dot test}

NDM before and after anesthesia are shown in Figure 1. There was no difference in NDM before anesthesia between the two groups. However, NDM in group E was significantly higher than in group $\mathrm{Y}$ from $30-90$ min after the end of propofol infusion. In group E,

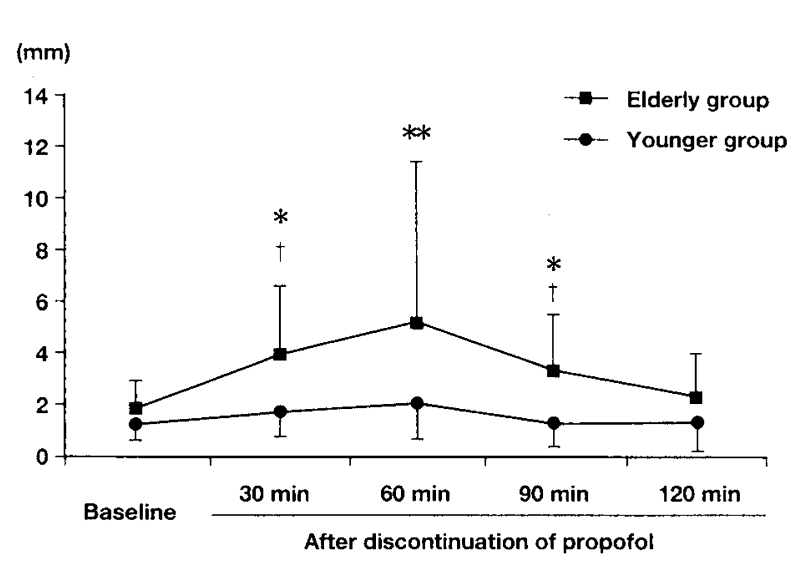

FIGURE 3 Trieger's dot test: maximum distance of dot missed. ${ }^{*} P<0.05$ vs younger group; ${ }^{*} P<0.01$ vs younger group; $\dagger P<$ 0.05 vs baseline; $\ddagger P<0.01$ vs baseline.

NDM increased significantly compared with baseline values from 30-90 min after the end of propofol infusion. SD and MDDM before and after anesthesia are shown in Figures 2 and 3. There were no significant differences before anesthesia between the two groups. However, significant increases of SD and MDDM in group E were observed from 30-90 min after the end of propofol infusion compared with group Y. In group E, SD and MDDM increased significantly compared with baseline values from 30-90 min after the end of propofol infusion.

\section{Discussion}

Altered and increased brain sensitivity to anesthetics have been widely reported in the elderly. ${ }^{1-5}$ Regarding $i v$ anesthetics, these changes in drug action are caused by aged-related alterations in drug disposition and end-organ sensitivity, or a combination of both. ${ }^{1,2,5}$ Schnider et al. ${ }^{3}$ reported that brain sensitivity to propofol decreased wakefulness in elderly patients. In the present study, early recovery time from sedation with propofol in the elderly, i.e., opening the eyes on command, sustaining a hand grip, and recalling their name, was not significantly different from that of younger patients despite the similar infusion rate of propofol in both groups. However, recovery of psychomotor function, which is associated with sophisticated and elaborate functions, was delayed in the elderly compared with younger patients. Recovery of psychomotor function from propofol sedation in the elderly may take two hours after discontinuation of propofol infusion. In the younger patients, the results 
of the Trieger's dot test did not differ significantly before and after propofol sedation. Impairment of psychomotor function due to propofol sedation may be detrimental to patients' well-being after local or regional anesthesia. Therefore, a more attentive and prolonged observation period may be necessary in elderly patients after anesthesia.

Propofol has also become a popular agent for sedation following local or regional anesthesia, ${ }^{6,7}$ because it has a short duration of action and rapid recovery with a minimum of side-effects, including a decreased incidence of nausea and vomiting. In this study, one elderly patient felt nausea postoperatively. Various mental changes, such as elation, euphoria, talkativeness and hallucination also occur after propofol anesthesia. Grant and Mackenzie ${ }^{13}$ reported that patients anesthetized with propofol woke up with euphoria and talkativeness. In our study, two patients experienced euphoria postoperatively in each group. Such mental changes may affect the results of the Trieger's dot test.

BIS values, which are derived from the EEG, have been introduced as a measure of the hypnotic level of anesthesia. The values change according to the depth of anesthesia or sedation, and decrease linearly with increasing anesthetic concentrations in patients of all ages. ${ }^{4}$ The BIS values at which patients are adequately sedated have been determined in many studies. 9,14,15 In the present study, the BIS values were maintained between 60 and 70 during propofol sedation in both groups. Since the recovery of psychomotor function in the elderly is prolonged compared with the younger patients, higher BIS values may be more appropriate in elderly patients.

Various psychomotor indices have been suggested to measure intermediate or late recovery from anesthesia. ${ }^{8,10,11,16,17}$ Larsen et al. ${ }^{18}$ measured psychomotor function using choice reaction time and the perceptive accuracy test following propofol and isoflurane anesthesia. They reported that those tests were effective and sensitive in assessing recovery of psychomotor function. Gupta et al., ${ }^{16}$ performing the Trieger's dot test and the p-deletion test to measure psychomotor recovery after propofol and isoflurane anesthesia, found that the Trieger's dot test was sensitive, but that the p-deletion test could not predict recovery in the individual patient. Thus, the Trieger's dot test is used widely for the assessment of intermediate and late recovery of cognitive and psychomotor functions after anesthesia. ${ }^{10}$ However, there are occasions when it is difficult to assess how many dots have been missed and interpretation can be somewhat subjective. ${ }^{16}$

In conclusion, we found that recovery of psychomotor function after propofol sedation in the elderly was delayed, although early recovery times in the elderly were not different from those of younger patients. Elderly patients may require a more prolonged observation period after cessation of sedation with propofol.

\section{References}

1 Minto CF, Schnider TW, Egan TD, et al. Influence of age and gender on the pharmacokinetics and pharmacodynamics of remifentanil. I. Model development. Anesthesiology 1997; 86: 10-23.

2 Schnider TW, Minto CF, Gambus PL, et al. The influence of method of administration and covariates on the pharmacokinetics of propofol in adult volunteers. Anesthesiology 1998; 88: 1170-82.

3 Schnider TW, Minto CF, Shafer SL, et al. The influence of age on propofol pharmacodynamics. Anesthesiology 1999; 90: 1502-16.

4 Katoh T, Bito H, Sato $S$. Influence of age on hypnotic requirement, bispectral index, and 95\% spectral edge frequency associated with sedation induced by sevoflurane. Anesthesiology 2000; 92: 55-61.

5 Homer TD, Stanski DR. The effect of increasing age on thiopental disposition and anesthetic requirement. Anesthesiology 1985; 62: 714-24.

6 Mackenzie N, Grant IS. Propofol for intravenous sedation. Anaesthesia 1987; 42: 3-6.

7 White PF, Negus JB. Sedative infusions during local and regional anaesthesia: a comparison of midazolam and propofol. J Clin Anesth 1991; 3: 32-9.

8 Wilson E, David A, Mackenzie N, Grant IS. Sedation during spinal anaesthesia: comparison of propofol and midazolam. Br J Anaesth 1990; 64: 48-52.

9 Nieuwenhuijs D, Sarton E, Teppema L, Dahan A. Propofol for monitored anesthesia care. Implications on hypoxic control of cardiorespiratory responses. Anesthesiology 2000; 92: 46-54.

10 Newman MG, Trieger N, Miller JC. Measuring recovery from anesthesia-a simple test. Anesth Analg 1969; 48: 136-40.

11 Randel GI, Levy L, Kothary SP, Pandit SK. Propofol versus thiamylal-enflurane anesthesia for outpatient laparoscopy. J Clin Anesth 1992; 4: 185-9.

12 Kearse LA Jr, Rosow C, Zaslavsky A, Connors P, Dershwitz $M$, Denman $W$. Bispectral analysis of the electroencephalogram predicts conscious processing of information during propofol sedation and hypnosis. Anesthesiology 1998; 88: 25-34.

13 Grant IS, Mackenzie N. Recovery following propofol ('Diprivan') anaesthesia-a review of three different anaesthetic techniques. Postgrad Med J 1985; 61(Suppl 3): 133-7.

14 Glass PS, Bloom M, Kearse L, Rosow C, Sebel P, Manberg 
$P$. Bispectral analysis measures sedation and memory effects of propofol, midazolam, isoflurane, and alfentanil in healthy volunteers. Anesthesiology 1997; 86: 836-47.

15 Iselin-Chaves IA, El Moalem HE, Gan TJ, Ginsberg B, Glass PSA. Changes in the auditory evoked potentials and the bispetral index following propofol or propofol and alfentanil. Anesthesiology 2000; 92: 1300-10.

16 Gupta A, Kullander M, Ekberg K, Lennmarken C. Assessment of recovery following day-case arthroscopy. A comparison between propofol and isoflurane-based anaesthesia. Anaesthesia 1995; 50: 937-42.

17 Larsen B, Seitz A, Larsen R. Recovery of cognitive function after remifentanil-propofol anesthesia: a comparison with desflurane and sevoflurane anesthesia. Anesth Analg 2000; 90: 168-74.

18 Larsen LE, Gupta A, Ledin T, Doolan M, Linder P, Lennmarken $C$. Psychomotor recovery following propofol or isoflurane anaesthesia for day-care surgery. Acta Anaesthesiol Scand 1992; 36: 276-82.

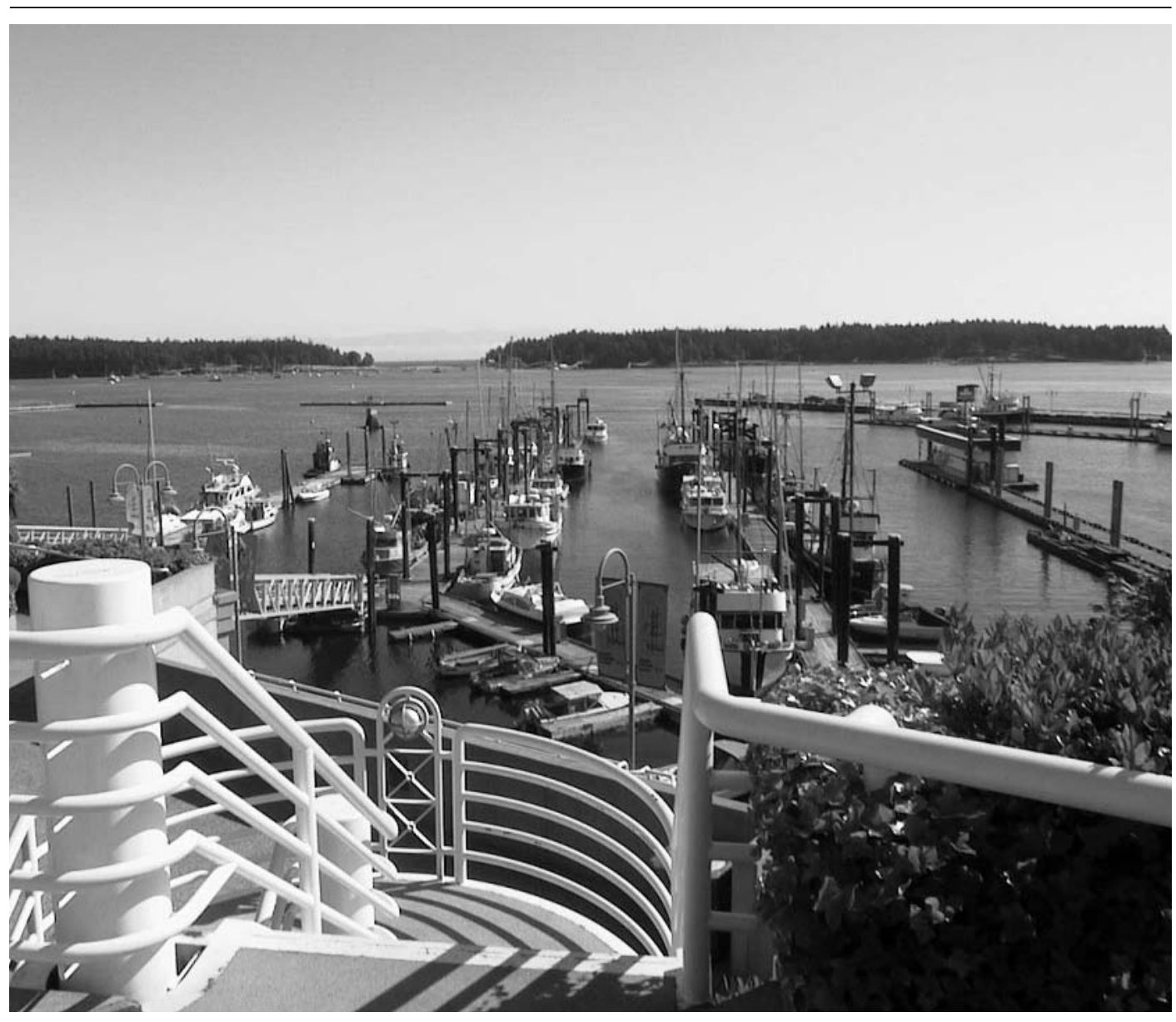

Nanaimo Bay, British Columbia - by Serge Lenis $M D$ 